\title{
Multidisciplinary management of clear-cell renal cell carcinoma in Africa and the Middle East: current practice and recommendations for improvement
}

\author{
This article was published in the following Dove Press journal: \\ Journal of Multidisciplinary Healthcare \\ 27 July 2015 \\ Number of times this article has been viewed
}

\author{
Jamal Zekri' \\ Lydia M Dreosti \\ Marwan Ghosn ${ }^{3}$ \\ Emad Hamada ${ }^{4}$ \\ Mohamed Jaloudi ${ }^{5}$ \\ Ola Khorshid ${ }^{6}$ \\ Blaha Larbaoui ${ }^{7}$ \\ 'College of Medicine, King Faisal \\ Specialist Hospital and Research \\ Centre, Alfaisal University, Jeddah, \\ Saudi Arabia; ${ }^{2}$ Department of Medical \\ Oncology, University of Pretoria, \\ Pretoria, South Africa; ${ }^{3}$ Faculty of \\ Medicine Hematology, Oncology \\ Department, Saint Joseph University, \\ Beirut, Lebanon; ${ }^{4}$ Faculty of Medicine, \\ Cairo University, Kasr Alainy, Cairo, \\ Egypt; ${ }^{5}$ Oncology Hematology \\ Department, Tawam Hospital, Al Ain, \\ Abu Dhabi, United Arab Emirates; \\ ${ }^{6}$ National Cancer Institute, Cairo \\ University, Kasr El Ainy, Cairo, Egypt; \\ ${ }^{7}$ Oncology Service, Université Djillali \\ Liabés, Sidi Bel Abbés, Algeria
}

\begin{abstract}
The management of renal cell carcinoma (RCC) has evolved considerably in recent years. This report represents the consensus of 22 relevant medical specialists from Africa and the Middle East region engaged in the management of RCC. Partial or radical nephrectomy is the standard of care for most patients with localized RCC. It is essential that patients are followed up appropriately after surgery to enable local and distant relapses to be identified and treated promptly. The treatment of advanced/metastatic disease has changed dramatically with the introduction of targeted therapies. Follow-up of these patients enables therapy optimization and assessment of response to treatment. There was universal agreement on the importance of management of RCC by a multidisciplinary team supported by a multidisciplinary tumor board. Barriers hindering this approach were identified. These included lack of awareness of the benefits of multidisciplinary team role, poor communication among relevant disciplines, time constraints, and specifics of private practice. Other challenges include shortage of expert specialists as urologists and oncologists and lack of local management guidelines in some countries. Solutions were proposed and discussed. Medical educational initiatives and awareness activities were highlighted as keys to encouraging cooperation between specialties to improve patients' outcome. Establishing combined genitourinary cancer clinics and formal referral systems should encourage a culture of effective communication. Joining forces with professionals in peripheral areas and the private sector is likely to help standardize care. Sustained action will be required to ensure that all patients with RCC in the region benefit from up-to-date care.
\end{abstract}

Keywords: Africa-Middle East, education, multidisciplinary, renal cell carcinoma

\section{Background}

Renal cell carcinoma (RCC) accounts for $80 \%-90 \%$ of malignancies affecting the kidneys and represents approximately $2 \%-4 \%$ of all malignancies. ${ }^{1}$ The classical histology is adenocarcinoma arising from the renal tubules, and the majority of cases are of the clear-cell carcinoma subtype. ${ }^{2}$ The main identified risk factors for developing RCC are smoking, obesity, and hypertension. ${ }^{1}$

The incidence of kidney tumors in Europe is 7.2-33.6/100,000 for males and $3.4-15 / 100,000$ for females, while the age-standardized incidence is $8.9-12.9 / 100,000$ for males and 4.1-5.9/100,000 for females. ${ }^{1}$ The incidence of RCC is rising in many parts of the world. In the USA, the incidence of kidney tumors has increased significantly in almost all racial/ethnic groups. ${ }^{3}$
Correspondence: Jamal Zekri College of Medicine, King Faisal Specialist Hospital and Research Centre, Alfaisal University, PO Box 40047, Jeddah 21499, Saudi Arabia Tel +966533129043 Email jmzekri@hotmail.com 
The age-standardized incidence of RCC in Africa and the Middle East (AfME) is in the range 1.8-4.8/100,000 for males and 1.2-2.2/100,000 for females. ${ }^{4}$ Although the incidence of RCC is lower in AfME than in the western world, it is nevertheless a cause of significant morbidity and mortality.

Effective management of malignant disease including RCC requires major effort from and collaboration among relevant health care professionals. Despite recognition of the benefits of a multidisciplinary approach, it is still not fully implemented in many countries of the AfME region.

With the exception of Saudi Arabia, national and regional RCC management guidelines are non-existent in the AfME region. $^{5}$

Motivated by these limitations, 22 urologists and oncologists from the AfME region met in Doha, Qatar, in February 2012 and Dubai, UAE, in March 2013 to share personal experience, describe local management practice, review examples of best practice, and develop practical guidance on implementing a multidisciplinary approach to RCC management. The draft was updated in November 2014. The following report represents a statement of consensus accepted by majority of the experts who participated in the discussions.

\section{Diagnosis}

RCC is increasingly being diagnosed incidentally, often as a result of increasing use of abdominal ultrasound or computed tomography (CT) examinations. Incidentally detected tumors are typically smaller, are diagnosed at earlier stage, and are of lower grade than symptomatic tumors ${ }^{6}$ and hence are associated with better survival. Some patients still present with the classic symptoms of hematuria, flank pain, and an abdominal mass. ${ }^{7}$

In AfME, the urologist is usually responsible for the definitive diagnosis of RCC and may receive referrals from nephrologists, general physicians, radiologists, and primary care physicians.

In line with international guidelines, diagnostic work-up normally includes physical examination, laboratory tests, and radiological investigations ( $\mathrm{CT}$ and/or magnetic resonance imaging $[\mathrm{MRI}])$ to characterize the renal mass. Accurate staging, using abdominal and chest CT or MRI to determine the extent of disease, is essential.

Many patients in the AfME region present at a late stage with metastatic disease, which highlights the importance of awareness programs and educational initiatives for early diagnosis.

\section{Treatment of localized disease}

Surgery remains the primary treatment for most cases with localized RCC and is the only potentially curative therapeutic approach. ${ }^{7}$ Newer interventional radiology techniques, such as radiofrequency ablation or cryoablation, may be appropriate in some cases, especially for smaller tumors $(\mathrm{T} 1 ; \leq 7 \mathrm{~cm}) .^{8-10}$

Surgery, partial nephrectomy (PN) or radical nephrectomy (RN), remains the standard of care for most patients with operable localized RCC. For small and accessible renal masses, PN (nephron-sparing surgery) is preferred, and current international guidelines recommend this as the standard of treatment for T1a tumors $(\leq 4 \mathrm{~cm}$ in greatest dimension). PN results in better preservation of renal function, fewer cardiovascular events, and lower overall mortality compared with RN. However, the complication rate is slightly higher. ${ }^{7,11,12}$ The EORTC Genitourinary Group compared PN and RN in a Phase III non-inferiority trial in 541 patients with small $(\leq 5 \mathrm{~cm})$, solitary T1-T2 N0 M0 tumors suspicious of RCC. ${ }^{12}$ It was concluded that both surgical approaches provide excellent oncologic results. In selected patients and with an experienced surgeon, PN can be performed laparoscopically. ${ }^{\text {? }}$

The expert group recommends multidisciplinary discussion of all cases, in particular cases of those with advanced tumors and those who may not tolerate surgical intervention. They also recognize that currently most cases in the region are not discussed in multidisciplinary meetings and highlight that ongoing education is needed to illustrate the benefits of multidisciplinary review, together with practical strategies to enhance collaboration and increase interaction and communication, including use of teleconferences.

\section{Follow-up after surgery}

A number of patient and tumor factors are recognized to impact the risk of recurrence after curative intent treatment. These include age, tumor size, pathological stage, lymph node status, tumor size, Fuhrman grade, histologic tumor necrosis, and symptoms. Some of these factors have been incorporated and validated in prognostic systems to quantify the likelihood of relapse. ${ }^{13-16}$

International guidelines recommend that the intensity of follow-up (frequency and type of investigations) should be tailored to the risk of relapse. The European Association of Urology has proposed an algorithm for follow-up that recommends ultrasound at 6 months and then $\mathrm{CT}$ scan and ultrasound in alternate years for 5 years for low-risk patients, with discharge from follow-up after a CT scan at 5 years. 
High-risk patients should be followed up with CT scans to 5 years and with CT scans in alternate years thereafter.

The expert group shares the view that RCC patients should be followed up regularly after surgery. The rationale for surveillance after surgery is to identify local and distant relapse as early as possible and facilitate timely referral for treatment. It was generally accepted that follow-up after local therapy (including surgery) should be provided by the urologist. The optimal follow-up schedules in two different clinical scenarios were discussed:

- a low-risk clear-cell RCC patient (T1, Nx, M0) treated with PN and

- a locally advanced clear-cell RCC patient (T3, N1, M0) treated with total $(\mathrm{RN})$ nephrectomy.

Less frequent follow-up was advocated for the low-risk patient (typically at 3-6 months for the first year and then annually for 3 years or 5 years) and more frequent follow-up for the high-risk patient (every 3 months for the first year, then 6 months for 5 years, and annually thereafter).

Regular clinical evaluation and laboratory tests were recommended as part of routine follow-up. Regular chest X-rays/ CT scans were unanimously recommended. Abdominal CT scans may not always be necessary, especially for the lowrisk patients and could be substituted by ultrasound of the kidneys/renal bed.

Although there was consensus on the importance of regular follow-up after surgery, it was noted that this is not necessarily fully implemented in many of the AfME regions' countries.

It was agreed that more education is needed to highlight the importance of follow-up. Urologists need to be fully aware of the benefits of treatment of relapse after surgery, in particular the benefits of salvage surgical treatments and those of targeted agents. This awareness should encourage multidisciplinary review and referral to the relevant specialist as soon as relapse is identified. There was an agreement that educational activities were likely to be more successful than guidelines alone. The importance of regular follow-up also needs to be communicated to patients.

\section{Treatment of advanced/metastatic disease}

Cytoreductive nephrectomy $(\mathrm{CN})$ may be indicated in patients with metastatic disease. In the immunotherapy era, prospective randomized trials showed a survival benefit for $\mathrm{CN}$ in patients with metastatic RCC (mRCC). ${ }^{17,18}$ It is not clear whether these data can be extrapolated to support $\mathrm{CN}$ in the era of targeted therapy. The majority of patients included in the pivotal Phase III trials of targeted agents had undergone $\mathrm{CN}$. In addition, recent retrospective data from large patient series showed improved outcome of patients treated with $\mathrm{CN}$ and targeted therapies compared with those who did not undergo CN. ${ }^{19,20}$

Arguments in favor of $\mathrm{CN}$ include ensuring that accurate histology information is available, the potential to palliate local symptoms, and the possible benefits of removing the primary tumor, which can be a source of further metastases and of growth factors. The expert group also discussed the arguments against $\mathrm{CN}$ as it may be associated with surgical morbidity and the risks of delaying the start of effective systemic therapy. ${ }^{21,22}$ All participants agreed that communication between oncologists and urologists is essential to reach a decision regarding the role of $\mathrm{CN}$ in each patient.

The expert group unanimously recommends the use of currently available prognostication scores for patients with $\mathrm{mRCC}$. There is general acceptance and endorsement of the Memorial Sloan Kettering Cancer Center and other similar scoring systems that stratify patients into good, intermediate, and poor-risk groups. ${ }^{23,24}$ Patients in these different prognostic groups are likely to benefit from different treatment options as guided by the landmark drug development trials and as reflected in international guidelines.

There have been dramatic changes in the treatment landscape for $\mathrm{mRCC}$ in recent years with the development of targeted agents, reflecting a greater understanding of the biology of the disease. Inhibitors of the vascular endothelial growth factor (VEGF) and its receptor and of the mammalian target of rapamycin signal transduction pathway have been shown to significantly improve clinical outcome. ${ }^{25} \mathrm{RCC}$ is relatively resistant to both chemotherapy and radiotherapy, and only a minority of patients achieved significant benefit from cytokine therapy. The introduction of novel targeted therapeutic agents has altered the natural history of this disease. The following agents have all been evaluated in Phase III clinical trials: sunitinib, bevacizumab (in combination with interferon-alpha), sorafenib, temsirolimus, everolimus, pazopanib, and axitinib. These agents are part of the standard treatment of patients with mRCC.

The results of Phase III trials of agents recommended for first-line use in clear-cell $\mathrm{mRCC}$ are summarized in Table 1. Sunitinib showed a significantly higher overall response rate and longer progression-free survival (PFS) than interferon. ${ }^{26,27}$ The combination of bevacizumab plus interferon-alpha was also more effective than interferon alone in two Phase III trials. ${ }^{28-31}$ 
Table I First-line treatment for RCC: Phase III trials

\begin{tabular}{|c|c|c|c|c|c|}
\hline Treatment & Number & $\begin{array}{l}\text { Prognostic group (\%) } \\
\text { G/I/P }\end{array}$ & ORR (\%) & $\begin{array}{l}\text { Median PFS } \\
\text { (months) }\end{array}$ & $\begin{array}{l}\text { Median OS } \\
\text { (months) }\end{array}$ \\
\hline Sunitinib vs & $375 / 375$ & $38 / 56 / 6$ & 47 vs 12 & II vs 5 & 26.4 vs 21.8 \\
\hline IFN- $\alpha^{26,27}$ & & $34 / 59 / 7$ & $P<0.001$ & $P<0.001$ & $P=0.051$ \\
\hline Bevacizumab + & $327 / 322$ & $27 / 56 / 9$ & 31 vs 13 & 10.4 vs 5.5 & 23.3 vs 21.3 \\
\hline IFN- $\alpha$ vs IFN- $\alpha^{30,31}$ & & $29 / 56 / 8$ & $P=0.0001$ & $P<0.00$ I & NS \\
\hline Bevacizumab + & $369 / 363$ & $26 / 64 / 10$ & 25.5 vs 13.1 & 8.4 vs 4.9 & 18.3 vs 17.4 \\
\hline IFN- $\alpha$ vs IFN- $\alpha^{28,29}$ & & $26 / 64 / 10$ & $P<0.0001$ & $P<0.001$ & NS \\
\hline Pazopanib vs & $155 / 78$ & $39 / 55 / 3^{a}$ & 32 vs 4 & II.I vs 2.8 & 22.9 vs 20.5 \\
\hline placebo $^{32,33}$ & & $39 / 53 / 3^{a}$ & & $P<0.0001$ & $\mathrm{NS}^{\mathrm{a}}$ \\
\hline Sunitinib vs & $553 / 557$ & $27 / 59 / 9$ & 25 vs 31 & 9.5 vs 8.4 & 29.1 vs 28.3 \\
\hline pazopanib $^{34,35}$ & & $27 / 58 / 12$ & $P=0.03$ & Non-inferior & NS \\
\hline Temsirolimus vs & $209 / 207$ & $-/ 31 / 69$ & 8.6 vs 4.8 & 5.5 vs 3.1 & 10.9 vs 7.3 \\
\hline IFN- $\alpha^{42}$ & & $-/ 24 / 76$ & NS & $P<0.001$ & $P=0.008$ \\
\hline
\end{tabular}

Note: ${ }^{\text {TTotal }}$ population.

Abbreviations: G, good; I, intermediate; IFN- $\alpha$, interferon-alpha; NS, not significant; ORR, overall response rate; OS, overall survival; P, poor; PFS, progression-free survival; RCC, renal cell carcinoma; vs, versus.

Pazopanib was superior to placebo as first- and second-line therapies (in treatment-naïve patients and after cytokines). ${ }^{32,33}$ It was compared with sunitinib in the Phase III COMPARZ trial, and the results showed non-inferiority. ${ }^{34-36}$ The two agents had different toxicity profiles. However, there has been much discussion and debate about the design of the trial, statistical considerations, and the timing of assessments for toxicity. ${ }^{37-40}$ These three options, sunitinib, pazopanib, or bevacizumab plus interferon, are recommended in many international guidelines as first-line therapy for good and intermediate prognosis of mRCC patients. ${ }^{7,25,41}$ The highest overall response rate and overall survival (OS) were observed with sunitinib (47\% and 26.4 months, respectively). ${ }^{27}$ Temsirolimus showed significant improvement in OS in a poor-risk population with three or more risk factors ${ }^{42}$ and is recommended in guidelines for these patients. ${ }^{7,25,41}$

The options for second-line therapy after a VEGF tyrosine kinase inhibitor (TKI) include everolimus or a second TKI. ${ }^{43-45}$ The RECORD-1 Phase III trial randomized 416 patients in a 2:1 allocation to everolimus or placebo plus best supportive care. The median PFS was longer in everolimus-treated patients (4.9 months vs 1.9 months, $P<0.001) .{ }^{44}$ The expert group discussed that $79 \%$ of patients in the RECORD-1 trial received two or more prior systemic treatments for advanced RCC, suggesting that everolimus can be effective in third and subsequent lines of treatment. ${ }^{46}$

In the Phase III AXIS trial, axitinib was compared with sorafenib (Figure 1). In this pure second-line trial, 723 patients were randomized to treatment with either axitinib or sorafenib. The objective response rate was significantly higher with axitinib (19\% vs 9\%; $P=0.0001) .{ }^{45}$ The primary endpoint was PFS (independently assessed), and this was significantly longer in the axitinib group than the sorafenib group (6.7 months vs 4.7 months; hazard ratio $0.665 ; P=0.0001)$. PFS was significantly longer with axitinib both in cytokine-treated patients and in those who had received first-line sunitinib. As expected in this setting, most patients will eventually experience disease progression. In the AXIS trial, 54\% of patients in the axitinib group and $57 \%$ of those in the sorafenib group received additional therapy, and $23 \%$ and $25 \%$ of those in each drug group, respectively, received two or more subsequent treatments. The availability of multiple salvage therapies limits the ability to interpret OS results.

The latest European Society for Medical Oncology guidelines for systemic treatment of metastatic clear-cell $\mathrm{RCC}^{25}$ recommend sunitinib, bevacizumab plus interferon or pazopanib as standard first-line therapy for good or intermediate risk patients (all, level of evidence I, grade of recommendation A) and temsirolimus for poor risk patients (II, A). The standard recommendations for second-line therapy after

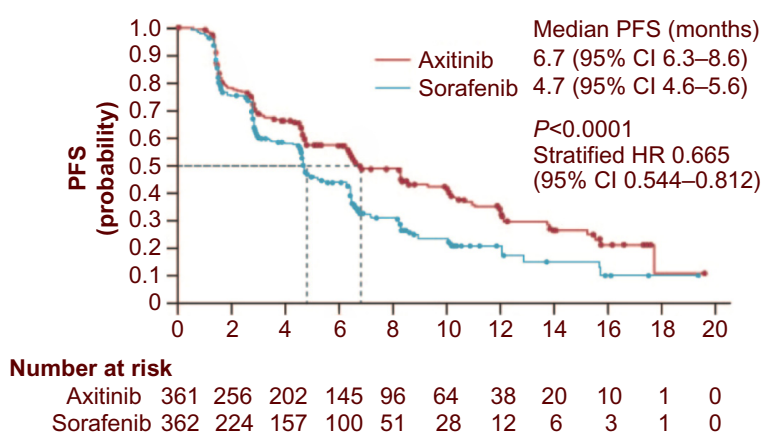

Figure I PFS in patients randomized to second-line treatment with axitinib or sorafenib. Reprinted from The Lancet Vol 378, Rini Bl, Escudier B, Tomczak P, et al. Comparative effectiveness of axitinib versus sorafenib in advanced renal cell carcinoma (AXIS): a randomised phase 3 trial; 1931-1939, Copyright 201 I, with permission from Elsevier. Abbreviations: PFS, progression-free survival; $\mathrm{Cl}$, confidence interval; $\mathrm{HR}$, hazard ratio. 
a TKI are axitinib (I, B) or everolimus (II, A). Standard thirdline recommendations are everolimus (II, A) after two TKIs or sorafenib (I, B) after a TKI and a mammalian target of rapamycin inhibitor.

Oncologists now have the therapeutic tools that could potentially convert $\mathrm{mRCC}$ into a chronic disease through optimal use of these agents. Treatment needs to be tailored to the characteristics of the patient and the extent and sites of metastatic disease.

Regular follow-up of patients receiving systemic treatment is essential, both to assess the response to treatment and to optimize therapy management. The optimal follow-up schedule for patients with $\mathrm{mRCC}$ receiving systemic targeted therapies was discussed. Typically, follow-up by the oncologist is recommended 1-2 weeks after starting therapy, at 1 month, and then every 6 weeks. This may be extended to 3 months in patients with no or minimum side effects. The expert group recommends radiological imaging for monitoring response and diagnosis of progression. Recommendations for therapy management are discussed in more detail below.

It was noted that most clinical trials have been undertaken in patients with clear-cell RCC and that more guidance is needed on the management of other histologies, including papillary and chromophobe RCC. ${ }^{47}$

In addition to targeted treatment, other modalities also have a role to play in managing advanced disease, including $\mathrm{CN}$, metastasectomy, stereotactic radiosurgery, and local radiotherapy. ${ }^{22,48-52}$ Surgical removal of limited metastases (metastasectomy) may have a role to play in the management of some cases of mRCC. In addition, consolidative metastasectomy is feasible in patients with a limited tumor burden after treatment with targeted agents. ${ }^{48,53}$ Stereotactic radiation can provide a precise form of radiation therapy, thus minimizing radiation damage to surrounding healthy tissues. ${ }^{50,51}$ Integrating these modalities in the treatment of mRCC puts more emphasis on adopting a multidisciplinary philosophy to achieve optimal outcome.

While all participants believe in the importance of regular follow-up by a multidisciplinary team (MDT), they recognized that it is not necessarily implemented optimally, especially outside specialist centers. More education is needed to highlight the importance of regular follow-up, including multidisciplinary review of imaging results. A significant majority of the expert group agree that the medical oncologist is the appropriate specialist to recommend, initiate, and manage systemic treatments. The role of other disciplines remains crucial at this stage when appropriate.

\section{Therapy management}

Therapy management is crucial to optimize the dose and duration of treatment and thus to achieve optimal outcome. ${ }^{54-57}$ The typical side effects of VEGF-TKIs include hand-foot syndrome, mucositis, diarrhea, nausea, and hypertension. The expert group emphasized the importance of proactive management of potential and early grade side effects. It was agreed that a clear distinction should be made between clinically relevant and serious side effects and those that are uncomfortable or inconvenient but less serious. Management of these two separate groups of side effects is different. Management of the former may necessitate dose reduction, limited treatment breaks, and treatment interruption if supportive measures fail. However, supportive treatment is usually all that is needed for the latter.

There is increasing evidence of an association between some adverse events of anti-VEGF-TKIs and clinical outcome. Hypertension, hand-foot syndrome, hypothyroidism, and, to lesser extent, myelosuppression were associated with longer PFS and/or OS in patients treated with sunitinib. ${ }^{58-61}$

Thus, the occurrence of adverse events should be regarded as a marker for adequate exposure to the drug and efficacy, encouraging continuation of therapy supported by adequate management of side effects rather than immediate interruption of treatment.

It was agreed that regular blood pressure measurement, monitoring of thyroid function (thyroid-stimulating hormone), and blood counts were essential to ensure that adverse events are proactively managed. These tests can be performed during follow-up visits (with frequency as mentioned in the previous section).

There was complete consensus among the expert group that frequent multidisciplinary follow-up is essential for the management of adverse events, especially early in the course of treatment. This will likely lead to early recognition of adverse events, which can then be managed promptly to avoid progression to serious grades. This will likely have a positive impact on maintaining quality of life.

There was strong support for the involvement of a specialist nurse empowered to monitor patients on targeted therapies. All agreed that management of side effects may require the specialist skills of other disciplines, including dermatologists, cardiologists, and internal medicine specialists, as appropriate. In addition, clinical pharmacists and specialist oncology pharmacists have an important role to play in therapy management. The expert group recognizes the shortage of well-qualified specialist oncology pharmacists in the region and that major efforts are needed in this area. 
There was a consensus that more education is needed, both for patients (about typical adverse events and the importance of prompt management) and for physicians and nurses about the need to follow up patients closely and manage adverse events proactively.

Open, clear, and transparent dialog between the patient and the health care professional is the cornerstone of modern medical practice. Such communication should be encouraged to facilitate an unambiguous plan of management and to achieve best possible outcomes.

\section{Neoadjuvant and adjuvant systemic therapy}

The efficacy of targeted therapy in $\mathrm{mRCC}$ raises the question of their potential use in adjuvant and neoadjuvant settings, mainly in patients with high-risk and locally advanced disease. ${ }^{22}$ As yet, there is no evidence to support the use of adjuvant therapy after nephrectomy, but there are several Phase III trials ongoing in patients at high risk of recurrence that should provide definitive answers. ${ }^{62}$

Similarly, there is no evidence to support the use of neoadjuvant therapy. ${ }^{63}$

There have been some reports of successful neoadjuvant targeted therapy, with downsizing of primary tumors to facilitate surgery. ${ }^{64}$ In a series of 30 patients, the median reduction in primary RCC tumors of clear-cell histology was $28 \%$ (absolute reduction $1.7 \mathrm{~cm}$ ) after using sunitinib. ${ }^{65}$

In another series of 24 patients, neoadjuvant axitinib induced a median reduction of primary renal tumor diameter by $28.3 \%$ with objective radiological partial response experienced in $11(46 \%)$ patients. ${ }^{66}$

However, the expert group agrees that adjuvant and neoadjuvant targeted therapies remain investigational and should not be part of the routine management of mRCC.

\section{Role of the multidisciplinary tumor board}

An agreement was reached that a multidisciplinary approach to cancer management is essential because of the everincreasing complexity of treatment and the wide range of interventions available. Input of specialist expertise across the medical disciplines has a very valuable part to play in improving patients' outcome. Indeed the MDT has a key role across the spectrum of cancer management, including diagnosis, staging, treatment, and palliative care. Multidisciplinary tumor board meetings can improve and optimize treatment planning. The multidisciplinary approach is regarded as a standard of care for diagnosis, classification, and treatment planning for almost all tumor sites. ${ }^{67-70}$ Cases are typically reviewed and discussed at a tumor board with representation from different relevant subspecialties. There is clear evidence that the introduction of multidisciplinary care is associated with improved survival and reduced variation in outcome. ${ }^{70}$ For urological malignancies and RCC in particular, the members would typically include:

- medical oncologist;

- urologist/urological surgeon;

- radiologist;

- pathologist (ideally a specialist uropathologist);

- radiation oncologist;

- clinical pharmacist;

- $\quad$ specialist site-specific nurse; and

- others as required (general surgeon, thoracic surgeon, neurosurgeon, interventional radiologist).

The expert group endorsed the concept of the MDT to manage RCC as an important approach to improve patients' outcome. The frequency of tumor board meetings should be decided by relevant teams at different management facilities depending on the caseload and the availability of experts. The specialist nurse is an important link between patients and physicians and plays a key role in educating patients about the disease and its management.

The responsibilities of the MDT should include agreeing/ confirming treatment plans, discussing alternative options, and assessing difficult or complex cases. The ideal would be for all cases to be reviewed and discussed at the tumor board, but again this depends on the resources available, and priority should be given to the more challenging cases.

With regard to the optimal time to initiate multidisciplinary review, it was believed that it should start at the time of first diagnosis of RCC, with the majority strongly supporting additional MDT review at the time of local progression or development of metastatic disease.

It was recommended that the urologist/surgeon should continue to be involved in the follow-up after referral for systemic therapy, to ensure that patients who are candidates for surgical resection in the future receive prompt intervention.

Possible barriers to multidisciplinary review in the AfME region are summarized in Table 2. Strategies for overcoming these barriers were proposed and are discussed below. These strategies focused on education programs and initiatives to encourage better communication. 


\section{Overcoming barriers to establishing an effective multidisciplinary approach}

Many proposals were made for strategies to overcome the barriers to effective multidisciplinary cooperation, including:

- initiatives to increase awareness of the benefits of the multidisciplinary approach;

- promotion of collaboration/communication between oncologists and urologists, which includes:

o combined genitourinary cancer clinics;

o formal system for referral;

o participation of junior clinicians in training;

o initiatives in peripheral areas;

o sharing of information between public and private sectors; and

o sharing of new clinical data;

- formation of MDT meetings or tumor boards where these do not exist, including creation of core teams with a special interest in RCC;

- shared follow-up of patients between different specialties as appropriate, eg, the continued involvement of a urologist after starting systemic therapy by the medical oncologist;

- increased awareness of the benefits of new therapeutic options;

- electronic patient records and facilitation of online case review and teleconferences;

Table 2 Barriers to multidisciplinary review and interdisciplinary referral

\begin{tabular}{|c|c|}
\hline Barriers to effective & Poor communication \\
\hline multidisciplinary cooperation & $\begin{array}{l}\text { Lack of awareness of the importance of } \\
\text { multidisciplinary cooperation } \\
\text { Time constraints and work load } \\
\text { Limited availability of relevant specialists } \\
\text { Logistical/organizational challenges } \\
\text { (especially in private practice) } \\
\text { Financial constraints }\end{array}$ \\
\hline $\begin{array}{l}\text { Specific barriers to referral } \\
\text { from urologist/surgeon to } \\
\text { oncologist }\end{array}$ & $\begin{array}{l}\text { Lack of follow-up of patients after surgery } \\
\text { Loss of patients to follow-up } \\
\text { Patients' social conditions } \\
\text { Shortage of oncologists } \\
\text { Costs of medication }\end{array}$ \\
\hline $\begin{array}{l}\text { Specific barriers to referral } \\
\text { of medically treated } \\
\text { patients for surgery }\end{array}$ & $\begin{array}{l}\text { Poor communication } \\
\text { Lack of awareness of benefits of } \\
\text { cytoreductive nephrectomy and } \\
\text { metastasectomy } \\
\text { Shortage of urologists/surgeons } \\
\text { Lack of continuity in the multidisciplinary } \\
\text { team }\end{array}$ \\
\hline
\end{tabular}

- guidelines, including institutional or national guidelines tailored to the therapies available (although meetings between specialties were considered more valuable);

- implementation of RCC registries to encourage collaboration; and

- partnerships with academic institutions and uro-oncology societies.

Greater availability and access to trained clinicians, including specialist urological surgeons, is needed in several countries; this would require additional training and sub-specialization.

Educational activities were repeatedly highlighted as key to encouraging cooperation between specialties to improve patient outcomes. Educational meetings could and should include the following:

- case conferences;

- multidisciplinary meetings;

- training/education for trainees and residents;

- small local meetings;

- large meetings with international experts;

- online conferences; and

- partnerships with professional societies.

The group recognizes that there is need for a strong will and determination to implement these proposals. There was general agreement that the multidisciplinary approach was being more widely implemented in some parts of the region. Specific examples included joint genitourinary oncology clinics in the United Arab Emirates and inclusion of a pathologist in the team (Jordan). It was noted that the number of multidisciplinary meetings has increased in several countries.

A well-developed strategy of multidisciplinary approach is adopted in Saudi Arabia (Table 3). This can be used as a model to be implemented in other parts of the region.

All recommendations were endorsed and further proposals were made, including sharing contact details of referring physicians to facilitate communication, more small meetings at which experience could be shared, and the formation of national action groups. There was continued strong support for all types of educational activities for different target audiences.

\section{Conclusion}

$\mathrm{RCC}$ is not a common malignancy. However, it carries significant morbidity and mortality mostly due to diagnosis at advanced stage. Surgery offers the best chance of cure. Local ablative measures may be suitable for selected cases. 
Table 3 Multidisciplinary approach in Saudi Arabia: implementing good practice

Experience in Saudi Arabia in implementing a multidisciplinary approach provides a valuable model for consideration and wider adoption. In major Saudi tertiary hospitals, a tumor board, consisting of urologists or uro-oncologists, genitourinary medical oncologists, radiation oncologists, a genitourinary pathologist, and an interventional radiologist, regularly meets to discuss all new and ongoing genitourinary cancer cases. All cases are documented and the agreed management plan signed. In some centers, the uro-oncologist, genitourinary medical oncologist, and radiation oncologist see patients in specialist multidisciplinary out-patient clinics in adjacent rooms to facilitate cooperation. Regular monthly city-wide meetings are held to provide a forum for discussion of difficult cases and management dilemmas as well as for providing an opportunity to share knowledge and experience.

There is also a nation-wide Saudi uro-oncology group, including all urooncologists, genitourinary medical oncologists, and radiation oncologists. This group organizes regular multidisciplinary meetings and educational activities, develops guidelines, and sponsors multidisciplinary research and has evolved into the National Uro-Oncology Society.

Educational activities in Saudi Arabia include an annual uro-oncology congress, an annual training course for senior residents, and an annual update course for practicing urologists and oncologists. The Saudi Genitourinary Cancers Guideline committee was formed in 2010 under the umbrella of the Saudi Oncology Society and the Saudi Urological Association and has published clinical management guidelines for RCC. ${ }^{5}$

Abbreviation: RCC, renal cell carcinoma.

Postoperative follow-up can detect early relapses, which occasionally can be treated surgically with the aim of long-term remission. $\mathrm{CN}$ is an acceptable first approach to management of advanced/metastatic disease in the era of targeted therapies. Approved targeted therapies are the standard of care in the management of advanced/metastatic disease guided by histology and risk stratification. Extensive knowledge and experience in prescribing these agents and in managing their side effects to optimize therapy is crucial to achieve best outcome.

The concept of multidisciplinary management was strongly endorsed and activities and initiatives to encourage it were identified and supported. In the short term, the model proposed for a multidisciplinary tumor board should be encouraged throughout the region, with an emphasis on the importance of collaboration between urologists and oncologists. In the medium term, regional meetings between relevant specialists would provide a forum for sharing best practice.

Although considerable progress has been made, it is recognized that sustained action will be required to ensure that all RCC patients in the region benefit from a multidisciplinary approach to treatment.

\section{Acknowledgments}

The authors thank all the oncologists and urologists who participated in the two meetings. The authors acknowledge the contribution of the following who reviewed the manuscript: Dalila Amokrane (Algeria), Yousfi Mostefa (Algeria), Mobarak Al Mansour (Saudi Arabia), Sultan Al Khatib (Saudi Arabia), Ashraf Abu Samrah (Saudi Arabia), Shingai Mutambirwa (South Africa), El Ghazi El Abbes (Morocco), Emad Hamada (Egypt), Ahmed Mosbah (Egypt), Salim Salhab (Lebanon), Khaled Ibrahim (Lebanon), Naeem Farah (Jordan), Hassan Jaafar (UAE), Henda Rais (Tunisia), Mehdi Afrit (Tunisia), and Mohamed Cherif (Tunisia). This article was produced following two meetings of oncologists and urologists during 2012 and 2013, organized and sponsored by Pfizer. Medical writing support was provided by Christine Drewienkiewicz of Choice Healthcare Solutions (London, UK) and was funded by Pfizer.

\section{Disclosure}

The authors declare that there are no conflicts of interest associated with this work.

\section{References}

1. Ljungberg B, Campbell SC, Choi HY, et al. The epidemiology of renal cell carcinoma. Eur Urol. 2011;60(4):615-621.

2. Reuter VE. The pathology of renal epithelial neoplasms. Semin Oncol. 2006;33(5):534-543.

3. Simard EP, Ward EM, Siegel R, Jemal A. Cancers with increasing incidence trends in the United States: 1999 through 2008. CA Cancer J Clin. 2012;62(2):118-128.

4. Ferlay J, Soerjomataram I, Ervik M, et al. GLOBOCAN 2012 v1.0, Cancer Incidence and Mortality Worldwide: IARC CancerBase No 11. 2013; 2015. Available from: http://globocan.iarc.fr. Accessed March 24, 2015.

5. Bazarbashi S, Al Othman K, Al Otaibi M, et al. Saudi Oncology Society clinical management guidelines for renal cell carcinoma. Urol Ann. 2011;3(Suppl):S3-S5.

6. Laguna MP, Algaba F, Cadeddu J, et al; Clinical Research Office of the Endourological Society Renal Mass Study. Current patterns of presentation and treatment of renal masses: a clinical research office of the endourological society prospective study. J Endourol. 2014;28(7): 861-870.

7. Ljungberg B, Bensalah K, Bex A, et al. EAU Guidelines on Renal Cell Carcinoma; 2014. Available from: http://uroweb.org/guideline/renalcell-carcinoma/. Accessed March 22, 2015.

8. El Dib R, Touma NJ, Kapoor A. Cryoablation vs radiofrequency ablation for the treatment of renal cell carcinoma: a meta-analysis of case series studies. BJU Int. 2012;110(4):510-516.

9. Joniau S, Tsivian M, Gontero P. Radiofrequency ablation for the treatment of small renal masses: safety and oncologic efficacy. Minerva Urol Nefrol. 2011;63(3):227-236.

10. Volpe A, Cadeddu JA, Cestari A, et al. Contemporary management of small renal masses. Eur Urol. 2011;60(3):501-515.

11. MacLennan S, Imamura M, Lapitan MC, et al; UCAN Systematic Review Reference Group; EAU Renal Cancer Guideline Panel. Systematic review of oncological outcomes following surgical management of localised renal cancer. Eur Urol. 2012;61(5):972-993.

12. Van Poppel H, Da Pozzo L, Albrecht W, et al. A prospective, randomised EORTC intergroup phase 3 study comparing the oncologic outcome of elective nephron-sparing surgery and radical nephrectomy for low-stage renal cell carcinoma. Eur Urol. 2011;59(4):543-552. 
13. Karakiewicz PI, Briganti A, Chun FK, et al. Multi-institutional validation of a new renal cancer-specific survival nomogram. J Clin Oncol. 2007;25(11):1316-1322.

14. Kattan MW, Reuter V, Motzer RJ, Katz J, Russo P. A postoperative prognostic nomogram for renal cell carcinoma. J Urol. 2001;166(1): 63-67.

15. Lam JS, Shvarts O, Leppert JT, Pantuck AJ, Figlin RA, Belldegrun AS. Postoperative surveillance protocol for patients with localized and locally advanced renal cell carcinoma based on a validated prognostic nomogram and risk group stratification system. $J$ Urol. 2005;174(2):466-472; discussion 472; quiz 801.

16. Leibovich BC, Blute ML, Cheville JC, et al. Prediction of progression after radical nephrectomy for patients with clear cell renal cell carcinoma: a stratification tool for prospective clinical trials. Cancer. 2003;97(7):1663-1671.

17. Mickisch GH, Garin A, van Poppel H, de Prijck L, Sylvester R. Radical nephrectomy plus interferon-alfa-based immunotherapy compared with interferon alfa alone in metastatic renal-cell carcinoma: a randomised trial. Lancet. 2001;358(9286):966-970.

18. Flanigan RC, Salmon SE, Blumenstein BA, et al. Nephrectomy followed by interferon alfa- $2 \mathrm{~b}$ compared with interferon alfa- $2 \mathrm{~b}$ alone for metastatic renal-cell cancer. $N$ Engl J Med. 2001;345(23):1655-1659.

19. Abern MR, Scosyrev E, Tsivian M, Messing EM, Polascik TJ, Dudek AZ. Survival of patients undergoing cytoreductive surgery for metastatic renal cell carcinoma in the targeted-therapy era. Anticancer Res. 2014;34(5):2405-2411.

20. Heng DY, Wells JC, Rini BI, et al. Cytoreductive nephrectomy in patients with synchronous metastases from renal cell carcinoma: results from the International Metastatic Renal Cell Carcinoma Database Consortium. Eur Urol. 2014;66(4):704-710.

21. Bex A, Powles T. Selecting patients for cytoreductive nephrectomy in advanced renal cell carcinoma: who and when. Expert Rev Anticancer Ther. 2012;12(6):787-797.

22. Kenney PA, Wood CG. Integration of surgery and systemic therapy for renal cell carcinoma. Urol Clin North Am. 2012;39(2):211-231, vii.

23. Motzer RJ, Mazumdar M, Bacik J, Berg W, Amsterdam A, Ferrara J. Survival and prognostic stratification of 670 patients with advanced renal cell carcinoma. J Clin Oncol. 1999;17(8):2530-2540.

24. Heng DY, Xie W, Regan MM, et al. External validation and comparison with other models of the International Metastatic Renal-Cell Carcinoma Database Consortium prognostic model: a population-based study. Lancet Oncol. 2013;14(2):141-148.

25. Escudier B, Porta C, Schmidinger M, et al; ESMO Guidelines Working Group. Renal cell carcinoma: ESMO Clinical Practice Guidelines for diagnosis, treatment and follow-up. Ann Oncol. 2014;25(Suppl 3): iii49-iii56.

26. Motzer RJ, Hutson TE, Tomczak P, et al. Sunitinib versus interferon alfa in metastatic renal-cell carcinoma. $N$ Engl J Med. 2007;356(2):115-124.

27. Motzer RJ, Hutson TE, Tomczak P, et al. Overall survival and updated results for sunitinib compared with interferon alfa in patients with metastatic renal cell carcinoma. J Clin Oncol. 2009;27(22):3584-3590.

28. Rini BI, Halabi S, Rosenberg JE, et al. Bevacizumab plus interferon alfa compared with interferon alfa monotherapy in patients with metastatic renal cell carcinoma: CALGB 90206. J Clin Oncol. 2008;26(33): 5422-5428.

29. Rini BI, Halabi S, Rosenberg JE, et al. Phase III trial of bevacizumab plus interferon alfa versus interferon alfa monotherapy in patients with metastatic renal cell carcinoma: final results of CALGB 90206. J Clin Oncol. 2010;28(13):2137-2143.

30. Escudier B, Pluzanska A, Koralewski P, et al; AVOREN Trial Investigators. Bevacizumab plus interferon alfa-2a for treatment of metastatic renal cell carcinoma: a randomised, double-blind phase III trial. Lancet. 2007;370(9605):2103-2111.

31. Escudier B, Bellmunt J, Négrier S, et al. Phase III trial of bevacizumab plus interferon alfa-2a in patients with metastatic renal cell carcinoma (AVOREN): final analysis of overall survival. J Clin Oncol. 2010; 28(13):2144-2150
32. Sternberg CN, Davis ID, Mardiak J, et al. Pazopanib in locally advanced or metastatic renal cell carcinoma: results of a randomized phase III trial. J Clin Oncol. 2010;28(6):1061-1068.

33. Sternberg CN, Hawkins RE, Wagstaff J, et al. A randomised, doubleblind phase III study of pazopanib in patients with advanced and/or metastatic renal cell carcinoma: final overall survival results and safety update. Eur J Cancer. 2013;49(6):1287-1296.

34. Motzer RJ, Hutson TE, Cella D, et al. Pazopanib versus sunitinib in metastatic renal-cell carcinoma. $N$ Engl J Med. 2013;369(8):722-731.

35. Motzer RJ, Hutson TE, McCann L, Deen K, Choueiri TK. Overall survival in renal-cell carcinoma with pazopanib versus sunitinib. N Engl J Med. 2014;370(18):1769-1770.

36. Motzer RJ, McCann L, Deen K. Pazopanib versus sunitinib in renal cancer. N Engl J Med. 2013;369(20):1970.

37. Wittes J. Pazopanib versus sunitinib in renal cancer. $N$ Engl J Med. 2013;369(20):1969.

38. Casper J, Schumann-Binarsch S, Kohne CH. Pazopanib versus sunitinib in renal cancer. $N$ Engl J Med. 2013;369(20):1969.

39. Iacovelli R, Verzoni E, De Braud F, Procopio G. First line treatment of metastatic renal cell carcinoma: two standards with different toxicity profile. Cancer Biol Ther. 2014;15(1):19-21.

40. Sun M, Trinh QD, Perrotte P, Karakiewicz PI. Words of wisdom: re: pazopanib versus sunitinib in metastatic renal-cell carcinoma. Eur Urol. 2014;65(5):1014-1015.

41. NCCN Clinical Practice Guidelines in Oncology (NCCN Guidelines). Kidney Cancer Version 3.2015; 2014. Available from: http://www.nccn. org/professionals/physician_gls/pdf/kidney.pdf. Accessed March 22, 2015.

42. Hudes G, Carducci M, Tomczak P, et al; Global ARCC Trial. Temsirolimus, interferon alfa, or both for advanced renal-cell carcinoma. N Engl J Med. 2007;356(22):2271-2281.

43. Motzer RJ, Escudier B, Oudard S, et al; RECORD-1 Study Group. Efficacy of everolimus in advanced renal cell carcinoma: a double-blind, randomised, placebo-controlled phase III trial. Lancet. 2008;372(9637): $449-456$.

44. Motzer RJ, Escudier B, Oudard S, et al; RECORD-1 Study Group. Phase 3 trial of everolimus for metastatic renal cell carcinoma: final results and analysis of prognostic factors. Cancer. 2010;116(18):4256-4265.

45. Rini BI, Escudier B, Tomczak P, et al. Comparative effectiveness of axitinib versus sorafenib in advanced renal cell carcinoma (AXIS): a randomised phase 3 trial. Lancet. 2011;378(9807):1931-1939.

46. Zustovich F, Lombardi G, Nicoletto O, Pastorelli D. Second-line therapy for refractory renal-cell carcinoma. Crit Rev Oncol Hematol. 2012;83(1):112-122.

47. Bellmunt J, Dutcher J. Targeted therapies and the treatment of non-clear cell renal cell carcinoma. Ann Oncol. 2013;24(7):1730-1740.

48. Alt AL, Boorjian SA, Lohse CM, Costello BA, Leibovich BC, Blute ML. Survival after complete surgical resection of multiple metastases from renal cell carcinoma. Cancer. 2011;117(13):2873-2882.

49. Dutcher JP, Mourad WF, Ennis RD. Integrating innovative therapeutic strategies into the management of renal cell carcinoma. Oncology (Williston Park). 2012;26(6):526-530.

50. Hanson PW, Elaimy AL, Lamoreaux WT, et al. A concise review of the efficacy of stereotactic radiosurgery in the management of melanoma and renal cell carcinoma brain metastases. World J Surg Oncol. 2012;10:176.

51. Ranck MC, Golden DW, Corbin KS, et al. Stereotactic body radiotherapy for the treatment of oligometastatic renal cell carcinoma. Am J Clin Oncol. 2013;36(6):589-595.

52. Bex A, Gore M, Mulders P, Sternberg CN. Recent advances in the treatment of advanced renal cell carcinoma: towards multidisciplinary personalized care. BJU Int. 2012;110(9):1289-1300.

53. Ljungberg $B$. The role of metastasectomy in renal cell carcinoma in the era of targeted therapy. Curr Urol Rep. 2013;14(1):19-25.

54. Kollmannsberger C, Bjarnason G, Burnett P, et al. Sunitinib in metastatic renal cell carcinoma: recommendations for management of noncardiovascular toxicities. Oncologist. 2011;16(5):543-553. 
55. Kollmannsberger C, Soulieres D, Wong R, Scalera A, Gaspo R, Bjarnason G. Sunitinib therapy for metastatic renal cell carcinoma: recommendations for management of side effects. Can Urol Assoc J. 2007;1(2 Suppl):S41-S54.

56. Schmidinger M, Arnold D, Szczylik C, Wagstaff J, Ravaud A. Optimizing the use of sunitinib in metastatic renal cell carcinoma: an update from clinical practice. Cancer Invest. 2010;28(8):856-864.

57. Schmidinger M, Larkin J, Ravaud A. Experience with sunitinib in the treatment of metastatic renal cell carcinoma. Ther Adv Urol. 2012;4(5): 253-265.

58. Rini BI, Cohen DP, Lu DR, et al. Hypertension as a biomarker of efficacy in patients with metastatic renal cell carcinoma treated with sunitinib. J Natl Cancer Inst. 2011;103(9):763-773.

59. Rautiola J, Donskov F, Peltola K, Joensuu H, Bono P. Sunitinib-induced hypertension, neutropenia and thrombocytopenia as predictors of good prognosis in metastatic renal cell carcinoma patients. BJU Int. Epub September 23, 2014.

60. Schmidinger M, Vogl UM, Bojic M, et al. Hypothyroidism in patients with renal cell carcinoma: blessing or curse? Cancer. 2011;117(3): 534-544.

61. Donskov F, Michaelson M, Puzanov I, et al. Comparative assessment of sunitinib-associated adverse events (AEs) as potential biomarkers of efficacy in metastatic renal cell carcinoma (mRCC). Presented at: European Society for Medical Oncology; September 28 to October 2, 2012; Vienna, Austria.

62. Janowitz T, Welsh SJ, Zaki K, Mulders P, Eisen T. Adjuvant therapy in renal cell carcinoma-past, present, and future. Semin Oncol. 2013;40(4): $482-491$.
63. Sciarra A, Cattarino S, Salciccia S, et al. The emerging role of targeted therapy in renal cell carcinoma (RCC): is it time for a neoadjuvant or an adjuvant approach? Crit Rev Oncol Hematol. 2012;81(2):151-162.

64. Amin C, Wallen E, Pruthi RS, Calvo BF, Godley PA, Rathmell WK. Preoperative tyrosine kinase inhibition as an adjunct to debulking nephrectomy. Urology. 2008;72:864-868.

65. Rini BI, Garcia J, Elson P, et al. The effect of sunitinib on primary renal cell carcinoma and facilitation of subsequent surgery. $J$ Urol. 2012;187(5):1548-1554.

66. Karam JA, Devine CE, Urbauer DL, et al. Phase 2 trial of neoadjuvant axitinib in patients with locally advanced nonmetastatic clear cell renal cell carcinoma. Eur Urol. 2014;66(5):874-880.

67. Clarke NW. Management of the spectrum of hormone refractory prostate cancer. Eur Urol. 2006;50(3):428-438; discussion 438-429.

68. Devitt B, Philip J, McLachlan SA. Team dynamics, decision making, and attitudes toward multidisciplinary cancer meetings: health professionals' perspectives. J Oncol Pract. 2010;6(6):e17-e20.

69. Ellis PM. The importance of multidisciplinary team management of patients with non-small-cell lung cancer. Curr Oncol. 2012; 19(Suppl 1):S7-S15.

70. Kesson EM, Allardice GM, George WD, Burns HJ, Morrison DS. Effects of multidisciplinary team working on breast cancer survival: retrospective, comparative, interventional cohort study of 13722 women. BMJ. 2012;344:e2718.
Journal of Multidisciplinary Healthcare

\section{Publish your work in this journal}

The Journal of Multidisciplinary Healthcare is an international, peerreviewed open-access journal that aims to represent and publish research in healthcare areas delivered by practitioners of different disciplines. This includes studies and reviews conducted by multidisciplinary teams as well as research which evaluates the results or conduct of such teams or

\section{Dovepress}

healthcare processes in general. The journal covers a wide range of areas and welcomes submissions from practitioners at all levels, from all over the world. The manuscript management system is completely online and includes a very quick and fair peer-review system. Visit http://www.dovepress.com/testimonials.php to read real quotes from published authors. 